\title{
Private Cloud: Effective Strategy in Developed Countries Case Study: Sudanese Universities
}

\author{
${ }^{1}$ Abdelrahman Osman, ${ }^{2}$ Hussien Abdulatif, ${ }^{3}$ Abusfian El-Gelany, ${ }^{4}$ Norma Alias \\ ${ }^{l}$ College of Computer at Al-Gunfudah, Umm Al-Qura University \\ ${ }^{2}$ Sudan Academy of Sciences \\ ${ }^{3}$ Sudan University for Science and Technology \\ ${ }^{4}$ Ibnu Sina Institute, UTM, Malaysia
}

\begin{abstract}
In order to achieve their business goals, educational organizations and institutions all over the World have become more dependent on information and communication technology (ICT). Internet services contributed to the improvement of the teaching-learning process, researches and other related activities. The cloud computing technology has effective applications, which offers students, staff, and administrative personnel access to educational resources at any time and from anywhere. Students have the opportunity to quickly and economically access various application platforms by sharing the resource based on cloud computing technology. In this paper, we investigated the benefits of adopting cloud computing services in higher education focusing on Sudanese universities, by sharing the hardware and software resources to minimize the cost. Private cloud computing proposed as a beneficial and practical solution. The benefits of adopting private cloud are highlighted. The solution took into account the unique features of Sudan and its related cultural context, flexibility, availability, security, quality of services and minimum operational cost. The solution highlights that the cloud computing technology is becoming an effective technology, for the reason that it is dynamic, scalable and useful in utilizing the limited resources.
\end{abstract}

Keywords: Cloud Computing; Higher Education; Sudanese Universities; Private Cloud

\section{Introduction}

Cloud computing applications provide high data processing for users by sharing the resources, to achieve users' demand and serving a wide range of information processing requests. Cloud computing has tremendous advantages that give this technology a maturity to rapidly be adopted in many areas including government, business, education, and medical facilities [1]. Many universities and institutions use cloud computing services partially or fully. The importance of using cloud computing in learning environments will be suitable for many universities in Sudan and have potential benefits.

The motivation of this paper is to show how cloud computing could support the higher education institutes and universities to provide their services in a wide range, and the students could access this service from anywhere at any time, especially in developed countries. The significance of using cloud computing in higher education helps economically in the best utilization of university resources, and helps in solving other problems. The cloud computing environment in higher education can help researchers, students, staff, and administrators to collaborate in a very comfortable and easy way to manage the environment.

\section{Cloud Computing Technology}

The Cloud computing is just an expansion of the idea of using the Internet to get through everything [2]. It can be considered as the fifth generation, after centralized computing generation, the personal computer generation, the server/client generation, and Web generation [3]. Cloud computing is divided into three general types, public, private, and the hybrid cloud (mixture between the previous two). "Cloud computing is a model for enabling ubiquitous, convenient, on-demand network access to a shared pool of configurable computing resources (e.g., Networks, servers, storage, applications, and services) that can be rapidly provisioned and released with minimal management effort or service provider interaction. This cloud model is composed of five essential characteristics, three service models, and four deployment models" [2]. Cloud computing components contain storage areas, computers linked to networks, programs and platforms. They are flexible enough to carry everything. It can provide the contents of the cloud to customers in the form of services (as a Service (aaS)), such as the provision of software as a service (SaS), providing hardware as a service (HaaS), sometimes called (Infrastructure as a Service (IaaS)), provide platform as a service (PaaS) [3], figure 1. 


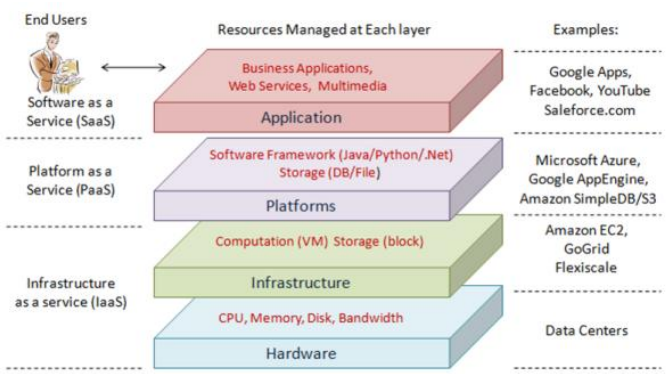

Fig. 1. Cloud Computing Services [4]

The various types of services available in the cloud are:

- Software as a Service (SaaS): This type is most interested to provide application and software service, which is anytime anywhere application access. SaaS can be used to provide applications over the internet as a service. The user does not need to install any application or software in his/her device. No need of buying special hardware, upgrading or updating of a software. No management and maintenance overhead. Examples of SaaS are Google Applications, Facebook, and YouTube [4].

- Platform as a Service (PaaS): The environment in which applications can be developed and executed. PaaS contains development tools, services for testing, deploying, and maintaining applications. Examples of PaaS are Google App Engine, Microsoft Azure, Amazon DB services [4].

- Infrastructure as a Service (IaaS): Computing resources or data centers that can be rented. Like Amazon Elastic Computing (EC2), Amazon S3 [4].

- The cloud can be also divided into four deployment models, private, public, hybrid, and community cloud [5].

\section{Cloud Computing Structure}

Cloud computing technology adopts different infrastructure to achieve more flexibility and covers more users, fig 2 shows the components of each structure [6].

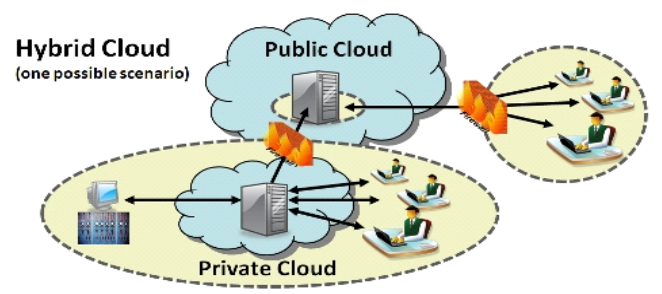

Fig2: Cloud Computing Structure [5]

\section{- Private Cloud}

Secure cloud is also called company cloud; it is an organization cloud to achieve marketing approach, which provides services like accessing, hosting, storage, platform and application. Private cloud can manage the accessing of users and control the use of applications, because it serves a limited number of users through an appropriate firewall [7].

Private cloud has many features like distributed computing, which allowed the companies network and datacenter administrators to effectively meet the needs of their users inside the organization [8]. A private cloud is designed for organizations that need more management and monitoring over their data than using a public cloud approach, which is third-party hosted service such as Amazon's Elastic Compute Cloud (EC2).

The private cloud structure is based on inside organizational access. Organizations are moving to private cloud for many reasons, for example to reduce energy cost, more IT performance and friendly business environment [9].

- Public cloud

The main characteristics of this cloud type are public access for different users without any need for authorized and different application environment [10].

- Hybrid cloud

Fig 2 shows the structure of hybrid cloud. This type of cloud computing structure combines between public and private cloud [11].

Hybrid cloud can be implemented for companies that need to implement their workloads in their private cloud and keeps others in public network [12]. 
Cloud Computing provides different levels of services like resources, applications, storages, communication, collaboration and infrastructure via services offered by the cloud service provider (CSP) [7].

All cloud computing types provide many services in order to take into account many features like:

- Agility: the ability to quickly add new resources or upgrade applications.

- Elasticity: the ability to scale up and down resource usage.

- A utility charging: you pay as a usage to minimize the operation cost.

\section{University Cloud Computing Structures}

As teaching operation changes and the existing teaching, learning methods cannot cover all the learning demands. Cloud computing technology provides effective services to achieve access and flexible network teaching platform. Cloud computing reduces the operating costs while improving quality of service and access to educational materials [13].

Education and academic institutions such as universities, which use cloud computing technology, will be benefited by all students and staff members, where lots of partnerships and secure academic data are stored [8]. Each university has many departments and its own semesters, where university students need to access high performance hardware and updated software. University services that are based on cloud computing that has the capacity of scaling and elasticity are more suitable for such environment [10].

Universities are using cloud computing technology, which has many services such as data storage, emails, information, academic resources, research applications and software [9]. All these services are provided anywhere and at any time for all faculties, administrators, staff members, students and disable students. Additional, cloud computing technology reduces IT maintenance and operation cost.

There are many challenges in adopting cloud computing in university environment.

- The security issue is the main challenge to adopt cloud computing in an academic area. Private cloud computing offers secure access to the network, which will deal with security challenges [14].

- The nature of changeable hardware resources and storage capacity, which is required in an academic environment such as labs.

Fig3 shows the university cloud computing structure and service levels.

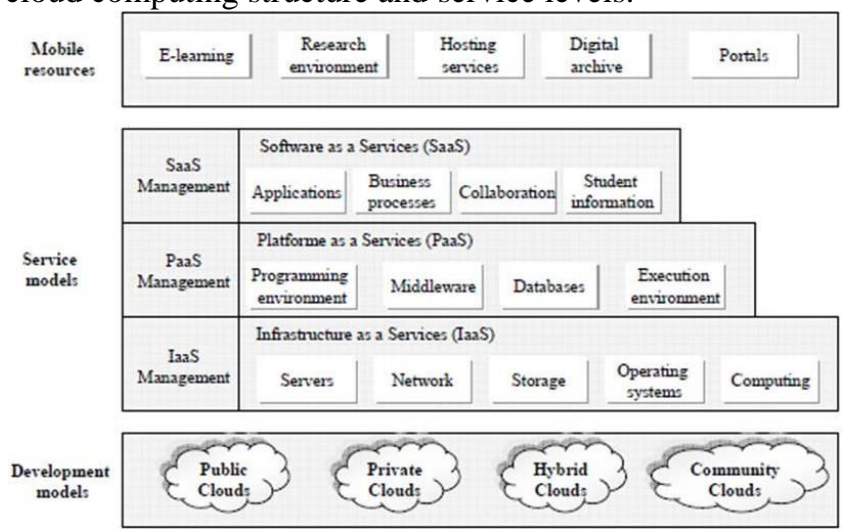

Fig3. Cloud Computing Structure For University [15]

Cloud computing offers many benefits for universities. They can be listed as:

- Reduced operation and maintenance costs.

- By using mobility many users can access university services.

- Flexible and scalable infrastructures.

- IT operation team can focus on innovation vs. Development and implementation.

- Can achieve "Data Center Greening".

- Some courses are shared by many colleges and departments like office applications, programming language, and multimedia courses, therefore there is no need to duplicate these courses, and one copy in the cloud is enough.

\section{Related Works}

There are broad related works, which discussed the use of cloud computing in higher education. In [5] Oyeleye Akin investigated the challenges of adopting cloud computing in Nigerian Universities. He revealed that the adoption of cloud computing in Nigerian Universities has a momentous impact on many aspects, on the other hand, the major challenges confronting the adoption of cloud are data insecurity, regulatory compliance concerns, lock-in and privacy concerns. Kiran Yadav [6] introduced a cloud education system for Indian 
educational institutions showing the benefits of adopting cloud in developing countries, but still the data security is considered as a problem, which needs to be solved.

In [7] a cloud environment is suggested for academic purposes in India. By viewing the benefits of cloud computing the researchers agree that working with the cloud will solve all the issues facing the education process. In [8] an academic cloud computing proposed to share resources between Saudi Arabian universities to support E-learning and D-learning and can benefit of cloud computing services to reduce the cost of hardware and software that were used at universities.

Abdullah Alshwaier in [1] studied the environment of cloud computing in education in Saudi Arabia and showed that universities can take advantage of cloud computing services in education in terms of low cost, increase processing speed, flexibility, and confidentiality. In addition, he presented a case study in the European countries and the U.S. who implemented cloud computing in education.

Truong in [19] presented a study on the possibility of using cloud computing in higher education and scientific research in developing countries. Where the focus was on the use of resources in cloud computing to provide high processing capabilities that were used in scientific research in higher education. Mohsen Abadi in [20], discuss the use of cloud computing in education and developed a model called the Education and Learning as a Service (ELaaS). Where he found that it was appropriate for educational institutions with limited education budgets to apply cloud computing technology. Divided educational institutions into two categories: mission and sensitivity.

Paul Pocatello in [21] has done a study, which proved that the systems of education and E-learning usually need sources of material and computer software. And pointed out that the application of cloud computing in education is the best solution. And that the application of cloud computing in education has its own characteristics. In his study, he measured the extent of the positive impact of the use of cloud computing in education in the long term. Sultan shows that many universities have used cloud computing in different countries like UK, US, and others [22]. Kashish Ara Shakil [23]. The author developed an effective framework for the management of educational data in the cloud computing, they highlighted the impact of data education management on the institution's quality. The proposed framework composed of three levels. The data center level, which consists of data center infrastructure, the service provider level, which provides different services to the customers and the educational or academic costumer level.

Marinela Mircea [24]. The author investigated the latest research on Cloud Computing as an alternative to IT technology and security. He also took into account the best practices for Cloud Computing usage within universities. The investigation, referring to the universities, which adopted Cloud Computing strategy. The researcher, encouraged and supported the adoption of Cloud solutions in universities, by improving knowledge in this field and providing a practical guide adapted to the university's structure. In order to be applicable in practice, the proposed model takes into account the university's architecture. Many research conducted in the field by using cloud computing in universities like [25], [26], [27], [21], [28], [29], [30], [31], [32] and [33]. Most of these researches, talked about reduce IT expenditures, collaboration in researches, using in e-learning, building virtual labs, and so on.

Table 1. Pros and Cons For Previous Researches

\begin{tabular}{|l|l|l|l|}
\hline \multicolumn{1}{|c|}{ Author } & \multicolumn{1}{|c|}{ Technology } & \multicolumn{1}{c|}{ Pros } & \multicolumn{1}{c|}{ Cons } \\
\hline $\begin{array}{l}\text { Akin } \\
\text { Kiran } \\
\text { Yadav }\end{array}$ & $\begin{array}{l}\text { Investigation } \\
\text { system }\end{array}$ & $\begin{array}{l}\text { Highlighted the challenges of } \\
\text { adopting cloud in Nigerian } \\
\text { universities }\end{array}$ & $\begin{array}{l}\text { Avoid the internet throughput } \\
\text { in Nigeria }\end{array}$ \\
\hline Singh & Investigation & $\begin{array}{l}\text { Highlighted the challenges of } \\
\text { adopting cloud in Indian universities }\end{array}$ & Avoid the QoS. \\
\hline Osman & Investigation & $\begin{array}{l}\text { Reduce the cost of hardware and } \\
\text { software }\end{array}$ & \multicolumn{1}{c|}{ Generally } \\
\hline $\begin{array}{l}\text { Abdullah } \\
\text { Alshwaier }\end{array}$ & Investigation & $\begin{array}{l}\text { Compare between Universities in } \\
\text { Saudi Arabia and USA. }\end{array}$ & Avoid the QoS. \\
\hline Truong & Investigation & $\begin{array}{l}\text { Focus on resources in cloud } \\
\text { computing }\end{array}$ & Avoid the security issue. \\
\hline $\begin{array}{l}\text { Mohsen } \\
\text { Abadi }\end{array}$ & $\begin{array}{l}\text { Developed a } \\
\text { model }\end{array}$ & With limited education budgets & Avoid the QoS. \\
\hline $\begin{array}{l}\text { Paul } \\
\text { Pocatello }\end{array}$ & Investigation & $\begin{array}{l}\text { Proved that the E-learning need } \\
\text { computer \& software }\end{array}$ & Avoid PaaS \& IaaS \\
\hline $\begin{array}{l}\text { Kashish } \\
\text { Ara Shakil }\end{array}$ & $\begin{array}{l}\text { Developed a } \\
\text { framework }\end{array}$ & Management of educational data & $\begin{array}{l}\text { Avoid the difference between } \\
\text { university structure }\end{array}$ \\
\hline $\begin{array}{l}\text { Marinela } \\
\text { Mircea }\end{array}$ & Investigation & $\begin{array}{l}\text { Takes into account the university's } \\
\text { architecture }\end{array}$ & $\begin{array}{l}\text { Cloud computing offerings as } \\
\text { a basic IT. }\end{array}$ \\
\hline
\end{tabular}




\section{Cloud Computing For Sudanese Universities}

Many benefits can be obtained when using cloud computing in Sudanese universities, for example:

- Unified services for all universities that are inexpensive and easy to be used. This leads to the reduction in cost of both maintenance and training.

- Getting all data in the same format. This can help the ministry of higher education getting access to all data of all the universities in an easy simple way.

- The scalability and flexibility of university resources.

- Reducing the cost of power consumption and sustaining universities green environment.

- All services will be available to different users from different universities, and any university can benefit from the resources of the other universities.

- Students can take advantage of cloud services (resources of universities) and access them from anywhere, at any time.

- The possibility of renting out cloud services to companies, institutions or researchers to take advantage of the resources of the university.

- Can take advantage of the cloud in teaching students in modern and innovative ways.

- Distance learning students can get benefit from the university's resources remotely.

- Gain expertise in the field of management, design and dealing with cloud computing.

- Develop standardized services that are suitable for all the other universities, thus no need to duplicate the same effort. Accordingly, the services are improved vertically towards better performance.

- Significant economic benefit lies in reducing resources, in all universities, especially that expensive one by sharing it between universities and any students from one university can use the resources of other universities.

- Cloud computing can open opportunities for distance students to perform practical part remotely. It can also help accommodate larger numbers of students by using virtualization.

- The cloud can be used to back the student's data, prevent universities from losing them, and protect data against natural disaster.

\section{Private Cloud As A Proposed Solution}

There are many problems and constraints with application offerings, service-level agreements, more importantly security issues. All of the cloud providers do not have the same capability for their technological levels. At Sudanese universities, a private cloud can be established to overcome these problems, fig 4. A shared community cloud can be built under the supervision of information technology department at ministry of higher education.

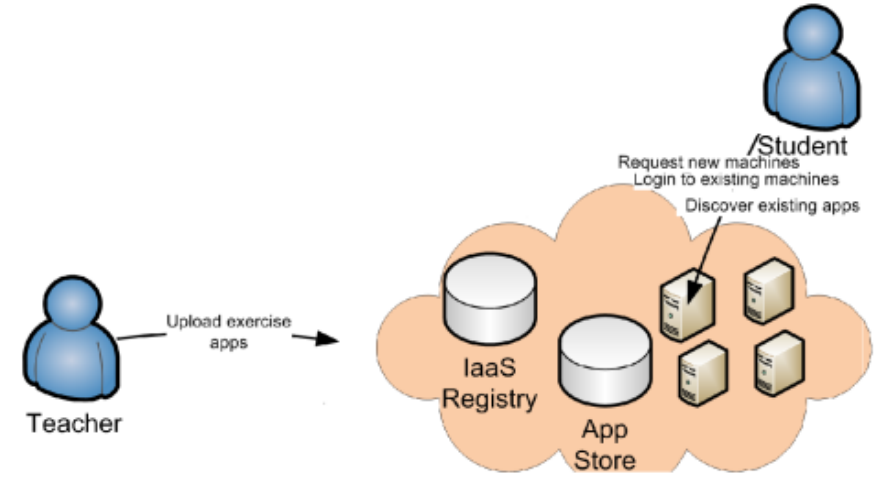

Fig. 4. The Proposed Private Cloud Computing For Sudanese Universities

The main advantage of the proposed solution is that it will be run by the universities. Therefore the management of cloud will be locally and the control and the protection rights are managed by the universities themselves.

Also, the proposed solution has many features like:

- Cover the psychological attitude and the culture of Sudanese students, which are different from other countries.

- Elasticity: user can access on-demand to compute and store data.

- Effective networking: systems on the private cloud were located inside the university and using virtual local area network (VLAN) and connected with the university local data center.

- Rapid deployment: purchase and provision of resources immediately.

- Transparent costing: see the true costs of IT without hidden costs. 


\section{Cloud Computing Technology}

With the status of budget limitation and the challenges of the growing needs, universities are facing problems in providing the necessary information technology (IT) support for research, education and development activities. This paper presents private cloud computing as a way for facilitating and solving many problems in Sudanese universities. The most important issue is the sharing of university resources that are not available to other universities and to facilitate a collaborative environment for teaching and researches.

The research is centered on the Sudanese student's culture, which is different from other counties. The students culture is an important factor, which is different from country to country. It should be added up by customizing the recent learning models. Taking into consideration the student's culture to improve their learning skills. So, the authors designed an effective model by integrating culture to maximize the benefits of mobile learning.

In Sudan, most of the regional universities outside Greater Khartoum have very limited resources and are often short of staff, and they cannot fulfil the required pedagogical outcome for their students. Accordingly, by using private cloud computing full advantage can be taken from accessing the resources of Greater Khartoum universities remotely, therefore, students from these regional universities can straightforwardly attend cloud based lectures and obtain other various materials.

\section{References}

[1]. Abdullah Alshwaier, A New Trend For E-Learning in KSA Using Educational Cloud, Advanced Computing: An International Journal ( ACIJ ), Vol.3, No.1, January 2012.

[2]. Peter Mell and Timothy Grance, The NIST Definition of Cloud Computing, National Institute of Standards and Technology Special Publication 800-145, 2011

[3]. Rajan, S. and A. Jairath. Cloud Computing: The Fifth Generation of Computing. Communication Systems and Network Technologies (CSNT), 2011 International Conference on. 2011. IEEE.

[4]. Zhang, Q., L. Cheng, and R. Boutaba, Cloud Computing: State-of-the-Art and Research Challenges. Journal of internet services and applications, 2010. 1(1): p. 7-18.

[5]. Chunmei Chi, The Trend of Cloud Computing in China, 2011.

[6]. Elgelany, Energy Efficiency for Data Center and Cloud Computing: A Literature Review, International Journal of Engineering and Innovative Technology (IJEIT) Volume 3, Issue 1, July 2013.

[7]. James W. Smith, Green Cloud A literature Review of Energy-Aware Computing, 2011.

[8]. Mell, P. and T. Grance. The NIST Definition of Cloud Computing, National Institute of Standards and Technology Special Publication 800-145, 2009.

[9]. Jiandun Li, Junjie Peng, Wu Zhang (2011), A Scheduling Algorithm for Private Clouds, Journal of Convergence Information Technology, Volume 6, Number 7, 1-9.

[10]. Chris Morris, Cloud Services and Technologies End-User Survey, 2011.

[11]. Christine Burns, Hybrid Clouds, Cloud Brokers, Big Data and Software-Defined Networking (SDN) Predicted to Be the Major Trends (SDN) Predicted to be the Major Trends in Cloud Computing in 2013, 2012.

[12]. Akin, O.C. and F.T. Matthew, The Impact and Challenges of Cloud Computing Adoption on Public Universities in Southwestern Nigeria. International Journal of Advanced Computer Science and Applications (IJACSA), 2014. 5(8)

[13]. BV Pranay Kumar, Effective Ways Cloud Computing Can Contribute To Education Success, Advanced Computing: An International Journal (ACIJ), Vol.4, No.4, July 2013

[14]. Sarvesh Kumar, Private Cloud: A Paradigm OF Cloud Computing With University Shared Data Center (USDC), International Journal of Computer \& Communication Technology, ISSN (PRINT): 0975 - 7449, Volume-3, Issue-6, 7, 8, 2012

[15]. Marinela Mircea and Anca Ioana, Using Cloud Computing in Higher Education: A Strategy to Improve Agility in the Current Financial Crisis, Volume 2011 (2011), Article ID 875547, Communications of the IBIMA, 15 pages DOI: 10.5171/2011.875547, 2011.

[16]. Yadav, K., Role of Cloud Computing in Education. International Journal of Innovative Research in Computer and Communication Engineering: p. 2320-9801.2014.

[17]. Singh, A. and M. Hemalatha, Cloud Computing For Academic Environment. 2012.

[18]. Osman, Abdelrahman, Saad Mamoun Abdalrahman, and Abusfian Elgelany. "Proposed Academic Cloud Computing for Saudi Universities and Higher Institutes." e-Learning" Best Practices in Management, Design and Development of e-Courses: Standards of Excellence and Creativity", 2013 Fourth International Conference on. IEEE, 2013.

[19]. Truong, H.-L., et al., Cloud Computing in Education and Research in Developing Countries. L. Chao, Cloud Computing for Teaching and Learning: Strategies for Design and Implementation, 2012: p. 64-80.

[20]. Alabbadi, M.M. Cloud Computing In Education and Learning: Education and Learning as a service (ELaaS). In Interactive Collaborative Learning (ICL), 2011 14th International Conference on. 2011. IEEE.

[21]. Pocatilu, P., F. Alecu, and M. Vetrici, Measuring The Efficiency of Cloud Computing For E-Learning Systems. WSEAS Transactions on Computers, 2010. 9(1): p. 42-51.

[22]. Sultan, N., Cloud Computing For Education: A new Dawn International Journal of Information Management, 2010. 30(2): p. 109116.

[23]. Kashish Shakil et al, An Effective Framework for Managing University Data using a Cloud based Environment, 2015

[24]. Marinela Mircea and Anca Andreescu, Using Cloud Computing in Higher Education: A Strategy to Improve Agility in the Current Financial Crisis, 2011.

[25]. Mircea, M. SOA, BPM and Cloud Computing: Connected for innovation in higher education. in Education and Management Technology (ICEMT), 2010 International Conference on. 2010. IEEE.

[26]. Britto, M., Cloud Computing in Higher Education. Library Student Journal, 2012. 7. 
[27]. Ercan, T., Effective Use of Cloud Computing in Educational Institutions. Procedia-Social and Behavioral Sciences, 2010. 2(2): p. 938-942.

[28]. Wyld, D.C., Moving to the Cloud: An introduction to Cloud Computing in Government. 2009: IBM Center for the Business of Government.

[29]. Bristow, R., et al., Cloud Computing and The Power to Choose. Educasuse Review, 2010. 45(3): p. 14-31.

[30]. Sasikala, S. and S. Prema, Massive Centralized Cloud Computing (MCCC) Exploration in Higher Education. Advances in Computational Sciences \& Technology, 2010. 3(2)

[31]. Katz, R., et al. Cloud Computing in Higher Education. in Educause. [Online],[Retrieved October 5, 2010], http://net. educause. edu/section_params/conf/CCW. 2010.

[32]. Ghazizadeh, A. Cloud Computing Benefits and Architecture in E-learning. in Wireless, Mobile and Ubiquitous Technology in Education (WMUTE), 2012 IEEE Seventh International Conference on. 2012. IEEE.

[33]. Hamid, Dayang Hjh Tiawa Awang Hj, et al. "Web-Based Service for Collaborative Authoring Learning Using Grid Portal." Open Source Technology: Concepts, Methodologies, Tools, and Applications. IGI Global, 2015. 1860-1872.

\section{AUTHOR PROFILES:}

Abdelrahman Osman received his $\mathrm{PhD}$ in Computer Sciences from University of Khartoum, in 2007. Currently, he is an Associate Professor at Umm Al-Qura University. His interests are in Parallel Processing, Distributed Systems and Cloud Computing.

Web site: https://www.researchgate.net/profile/Abdelrahman_Osman3.

Hussien Abdulatif received his MSc degree in Electrical Engineering from Sudan University, in 2003. Currently, he is a PhD student at Sudan Academy of Sciences. His research interests include Cloud Computing and Computer Networks.

Abusfian El-Gelany received his PhD degree in Computer Sciences from Sudan University in 2015. Currently, he is a Lecturer at Al-Jouf University. His research interests include Cloud Computing, Distributed systems.

Norma Alias received the her $\mathrm{PhD}$ in (Industrial Computing: Parallel Computing). Currently, she is an Associate Professor at UTM. Her interests are in Industrial Computer, Numerical Computation, Scientific Computing, HPC on Distributed Parallel Computer Systems, Grid Computing and software development. 